\title{
O ensino das ciências básicas na área da Saúde
}

\author{
GERHARD MALNIC \\ - MAGDA CARNEIRO SAMPAIO
}

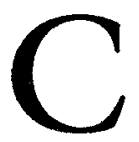

om a reforma universitária de 1968 , as ciências básicas de várias Unidades Universitárias do setor da Saúde foram unificadas no Instituto de Ciências Biomédicas. $O$ argumento fundamental desta reforma foi a idéia que todas as áreas da saúde, incluindo Medicina Humana e Veterinária, Odontologia, Farmácia, Educação Física, Enfermagem, Fisioterapia, Terapia Ocupacional, Fonoaudiologia e Nutrição se baseiam em um conjunto único de Ciências, têm muito mais em comum do que aquilo que as possa separar. $O$ acerto dessa medida tem sido muito discutido, e sem dúvida há muitos fatores favoráveis à idéia, mas também alguns desfavoráveis. Mas não se pode negar que desta forma foi possível criar Departamentos fortes, os quais foram se consolidando progressivamente, levando à maior homogeneidade do ensino destas Ciências na Universidade e contribuindo, na maioria dos casos, para a melhoria do ensino nestes setores. Olhando para trás, observa-se que existe clara tendência de os conjuntos de docentes destes Departamentos, que inicialmente tendiam a manter suas características de origem, isto é, sua qualificação como médicos, dentistas, veterinários etc., transformarem-se primordialmente em anatomistas, fisiologistas ou parasitologistas, independentemente da área de aplicaçăo futura dessas ciências. Esta tendência sem dúvida foi positiva, e foi a intenção original da reforma que deu origem a tais modificaçóes. Por outro lado, algumas das Faculdades e Escolas que originaram esses Departamentos até hoje se sentem despojadas de importantes elementos de sua estrutura curricular e, particularmente, científica já que, como veremos adiante, as ciências biomédicas básicas constituem talvez um dos setores de maior tradição e excelência dentro da ciência brasileira. A solução para essa ambivalência, hoje, dificilmente poderia ser a volta à situação antiga, pois o ICB atingiu identidade própria e independência bastante consolidada. A maior parte de seus docentes já perdeu os laços com as Unidades de origem, principalmente porque são poucos os que iniciaram sua vida acadêmica ainda no sistema antigo. Uma soluçáo para essa dificuldade deverá, ao contrário, ser baseada na estreita interação do Instituto de Ciências Biomédicas com as Faculdades mais profissiona- 
lizantes, de modo a fornecer a estas contribuiçáo para aprimorar o seu embasamento científico, participando, por sua vez, os setores mais aplicados com objetivos de pesquisa de natureza mais prática, que possam fecundar a pesquisa nos Departamentos básicos.

Dentro dos objetivos da presente análise, vale definir quais são as ciências que compóem o Instituto de Ciências Biomédicas. A título de preâmbulo é importante esclarecer que, nos dias atuais, os limites entre as ciências que classicamente fazem parte do embasamento das ciências da saúde estão se tornando cada vez menos distintos, estando a interdisciplinaridade na ordem do dia. Tanto assim que a ciência biomédica mais básica de todas, a Bioquímica, e que por motivos de organizaçáo das Unidades Universitárias pertence ao Instituto de Química, se bem que poderia perfeitamente fazer parte do ICB, hoje se difunde por praticamente todos os setores das ciências da vida. Isto é particularmente verdade no caso da Biologia Molecular, que trata da estrutura, função e gênese das moléculas que embasam a funçáo celular. Nenhum Departamento que aspire à modernidade na Ciência Biológica em geral, e na Ciência Biomédica em particular, pode deixar de ter firme âncora nesta área, que talvez seja aquela que tenha demonstrado maiores e mais relevantes progressos nas últimas décadas. Área também básica para a Ciência Biomédica é a Genética, esta incluída no Instituto de Biociências. Os mencionados são apenas alguns exemplos de interdisciplinaridade que ultrapassam os limites do Instituto e outros mais poderiam ser citados, como, por exemplo, a Psicologia, sem falar de outras, mais básicas ainda, como Matemática, Física e Química, fundamentos para qualquer visão mais científica das Ciências da Vida. Vê-se que a evolução da moderna ciência tem solapado os limites não só entre Departamentos mas também entre os próprios Institutos, mostrando, cada vez mais, que a ciência é uma só; por fazermos parte de um Departamento ou de um Instituto năo podemos nos restringir a determinado tipo de metodologia, de procedimentos ou de raciocínio; é essencial estar com a mente aberta para os progressos que possam afetar nosso campo de trabalho onde quer que tenham sua origem. Portanto, as velhas divisóes entre Departamentos e Institutos estão ultrapassadas do ponto de vista conceitual, e servem atualmente só como base de uma divisão administrativa e burocrática. Daí ser muito difícil basear a discussão sobre a estrutura de Unidades Universitárias em antecedentes históricos, hoje já ultrapassados pelo progresso da Ciência.

Feita esta ressalva, vejamos quais são os setores que hoje compóem o ICB. Temos inicialmente as Ciências Morfológicas, que incluem a Anatomia, a Histologia e a Embriologia, afeitas originalmente ao estudo - macroscópico e microscópico - da estrutura dos seres vivos, 
particularmente do homem e de sua evoluçáo embriológica. Atualmente, importante área que tem se sobressaído nestas ciências é a Biologia Celular, que trata do estudo da estrutura e função dos componentes celulares e subcelulares in vipo. A parte da Biologia Celular incluída nas Ciências Morfológicas é aquela que utiliza as técnicas microscópicas características desta área. Temos em seguida um conjunto de disciplinas denominado de Ciências Fisiológicas, que inclui, no ICB, a Fisiologia, a Biofísica e a Farmacologia. Estas ciências analisam a função das células e dos órgáos dos seres vivos, no caso de Fisiologia e Biofísica, que se distinguem mais com base na metodologia para atingir tais objetivos. A Farmacologia estuda a maneira pela qual várias substâncias, agentes farmacológicos, de origem natural ou derivadas da síntese química, afetam a funçáo de células e órgáos. Por fim, temos um conjunto de disciplinas que aborda os processos de interação entre parasitas e hospedeiros, principalmente por parte de microorganismos patogênicos, objeto de estudo da Microbiologia (incluindo Bacteriologia, interessada na infecção por bactérias, Virologia, por vírus e Micologia, por fungos), além de Parasitologia, que estuda a infecçáo por parte de protozoários (por exemplo, amebas) e helmintos (entre outros, vermes). Ainda são estudados os mecanismos de proteçáo dos organismos vivos contra essas infecçóes, objetivo da Imunologia, que inclui a análise de processos químicos e celulares de defesa.

Os setores de pesquisa científica incluídos no Instituto de Ciências Biomédicas, isto é, as bases científicas das ciências da Saúde, estáo entre aqueles de maior tradiçáo e desenvolvimento dentro da ciência brasileira. Ciências que tiveram seu primeiro impulso por ocasião da criação de Institutos de Saúde Pública no Brasil, na época da virada do século XIX para XX. Os Institutos de Manguinhos (hoje Fundação Oswaldo Cruz), do Rio de Janeiro, e Butantan, de Sáo Paulo, foram criados àquela época, isto é, em 1899. Ainda anteriormente, em 1890, originou-se o Instituto Bacteriológico de São Paulo, hoje Adolfo Lutz, sede de importantes pesquisas em microbiologia e áreas afins. Destinavam-se a combater epidemias como a febre amarela, no Rio de Janeiro, a peste bubônica, no porto de Santos e de produzir soros e vacinas para combater doenças tropicais. Estes Institutos, no entantó, não se limitaram a investigar questōes ligadas à aplicaçáo imediata do conhecimento médico; a extraordinária visão de seus fundadores, Oswaldo Cruz no Rio de Janeiro e Vital Brasil e Adolfo Lutz em Sáo Paulo, possibilitou a criação, nesses Institutos, de laboratórios de Bioquímica, Fisiologia, Farmacologia, Microbiologia, Parasitologia e Patologia, que abrigaram cientistas de renome como Carlos Chagas, Gaspar Viana e Álvaro e Osório de Almeida, no Rio, e Klobuzitsky, Karl Slotta e Thales Martins, 
no Butantan, em São Paulo. Do trabalho desses pesquisadores resultaram importantes conhecimentos, como o ciclo da doença de Chagas, os soros antiofídicos e muitos outros. Institutos de natureza semelhante foram criados mais tarde, como o Biológico em São Paulo, formado em 1927 , inicialmente com a finalidade de combater a broca do café; também abrigou pesquisadores como Rocha Lima, descobridor do vetor do tifo exantemático, Otto Bier, pioneiro da Microbiologia e da Imunologia brasileiras, e Maurício da Rocha e Silva, que descobriu a bradicinina, substância humoral de grande importância em Fisiologia e Farmacologia. Sendo o desenvolvimento da pesquisa científica nas universidades brasileiras um processo mais tardio, consolidado a partir de 1935 com a fundação da Universidade de São Paulo, durante muito tempo tais Institutos constituíram o celeiro que abastecia de cientistas as universidades, bem como outras instituiçóes que deles necessitavam. Muitos dos atuais docentes universitários são descendentes mais ou menos diretos destes primeiros centros de pesquisa nacionais. Apesar de na atualidade as universidades terem se tornado os centros de pesquisa mais vigorosos do país, os Institutos citados ainda constituem importantes núcleos científicos em muitas das áreas biomédicas básicas. Por outro lado, o ICB e institutos universitários congêneres sentiram importante influência de professores estrangeiros que aqui aportaram, trazidos em parte pelos fundadores da Faculdade de Medicina de.São Paulo, a partir de 1913, instituiçáo que contribuiu, na década de 30, com a criação, apoiada pela Fundação Rockefeller, do tempo integral e do numerus clausus de alunos ao meio universitário brasileiro. Entre estes docentes convém lembrar Brumpt (Parasitologia), Bovero (Anatomia), além de outros formados no país, como Samuel Pessoa (Parasitologia), Alberto Carvalho da Silva (Fisiologia), Luis Junqueira (Histologia) etc. Importante contribuiçăo ao meio científico paulista da área biológica proveio também daqueles cientistas que vieram à Faculdade de Filosofia, Ciências e Letras da USP, no período de sua fundação, para as áreas de Biologia, Química e Física. Atualmente, o aperfeiçoamento científico dos docentes da área baseia-se, em grande parte, além da pósgraduação, que abordaremos adiante, em estágios de pós-doutorado por períodos prolongados (um ou mais anos) em importantes centros de pesquisa do exterior.

\section{O ensino de graduação}

O ensino ministrado pelo ICB nestas múltiplas áreas tem grande amplitude e é dirigido a cerca de $\mathbf{9 0 0}$ alunos por ano, com mais de $\mathbf{7 0 0 0}$ matrículas em 83 disciplinas. Este ensino envolve significativa parcela de exercícios práticos que necessitam de forte infra-estrutura laboratorial, fornecimento de animais e suprimentos especializados, necessidadés que 
consomem boa parte do orçamento do Instituto. Por outro lado, o esforço dos seus docentes tem conseguido angariar fundos para pesquisa, que indiretamente também favorecem o ensino de graduação e de pósgraduação, da ordem de $\mathbf{9 0}$ milhōes de dólares nos últimos cinco anos. Tem contribuído para tal esforço em nível de ensino de graduaçáo, a edição de várias obras didáticas de grande circulação, como os livros de Histologia e Citologia de Junqueira e Carneiro, traduzidos para muitas línguas estrangeiras, a Microbiologia de Trabulsi, a Fisiologia de Mello Aires, a Farmacologia de Oga e Zanini, além de outros mais especializados.

\section{Pós-graduação e pesquisa no ICB}

A forte base em pesquisa científica constitui a sustentaçáo da pósgraduaçáo do Instituto; a presença de numerosos pós-graduandos nos seus laboratórios tem contribuído sobremaneira para o avanço da sua pesquisa. Cada um dos sete Departamentos do Instituto conta com pósgraduaçáo em sua área; além disso, o Instituto participa da pós-graduação em Biotecnologia, junto com várias outras Unidades da USP e com forte participaçáo dos Institutos Butantan e Adolfo Lutz, e da pósgraduação em Neurociências, também interunidades. $O$ Instituto conta, neste momento, com 195 alunos matriculados no mestrado e 173 no doutorado. A partir do início dos programas de pós-graduação, em 1972, já formou $\mathbf{4 0 2}$ mestres e $\mathbf{4 4 3}$ doutores. A maioria desses cursos, pela classificação da CAPES, obteve o nível A.

A atividade científica no ICB é intensa e variada, levando anualmente à publicação de mais de 100 trabalhos completos em revistas de circulaçáo internacional. Este resultado, sem dúvida, decorre da profissionalizaçáo do ensino e da pesquisa entre os docentes do Instituto que, em sua grande maioria, se dedicam a essas atividades em tempo integral. São inúmeras as linhas de pesquisa abordadas nos laboratórios do Instituto. Citaremos só algumas, nas diversas áreas, a título de exemplo.

- Atomia - ultra-estrutura e imunohistoquímica de diversos tecidos: tecido nervoso, glândulas salivares, dentes e músculos.

- Histologia - biologia da reprodução: implantação embrionária e decidualizaçáo; funçăo do trofoblasto; regeneraçăo de nervos periféricos; proteínas envolvidas no controle da contraçáo muscular; proliferação e diferenciaçáo celular da mucosa gástrica; secreção celular e histofisiologia das glândulas salivares.

- Fisiologia - transporte através de membranas epiteliais; túbulo renal, biofísica de epitélios, canais iônicos; biologia molecular de 
transportadores de membrana em células renais; inter-relaçóes hodológicas de estruturas neurais relacionadas à formaçáo reticular $\mathbf{e}$ ao sistema límbico; bases neurais do comportamento: cronobiologia, fisiologia e ontogênese do ciclo vigília/sono; mecanismos celulares e moleculares da regulaçáo de hormônios, particularmente de insulina e hormônios tiroideanos; metabolismo de linfócitos e macrófagos e sua regulação.

- Farmacologia - farmacologia da inflamação; processos fisiopatológicos que modulam a resposta inflamatória; farmacologia da hipertensão, incluindo o papel do endotélio vascular e do óxido nítrico em modelos de hipertensão arterial; neuropsicofarmacologia, abordando processos adaptativos neurais a drogas psicoativas; metabolismo de neuropeptídeos, enzimas que os metabolizam, e sua biologia molecular.

- Microbiologia - estudo de bactérias enteropatogênicas: mecanismos celulares e moleculares; genética microbiana e engenharia genética; micologia médica; virologia: imunologia viral; microbiologia ambiental $\mathrm{e}$ industrial.

- Parasitologia - biologia celular, molecular e imunologia de parasitos: modelos plasmodium, trypanosoma, leishmania, amebas entre outros.

- Imunologia - imunologia e imunopatologia de doenças parasitárias, bacterianas e fúngicas; imunologia da inflamaçăo.

Gerhard Malnic é professor do Instrituto de Ciências Biomédicas da USP.

Magda Carneiro Sampaio é presidente da Comissão de Pós-Graduaçăo do Instituto de Ciências Biomédicas da USP. 